\title{
Design of a contactless powered and piezoelectric-actuated tool for non-resonant low-frequency vibration-assisted machining of brittle-hard materials
}

\author{
Jens Brier ${ }^{1}$ • Friedrich Bleicher ${ }^{1}$ \\ Received: 8 January 2021 / Accepted: 7 June 2021 / Published online: 23 June 2021 \\ (C) The Author(s) 2021
}

\begin{abstract}
Ultrasonic-assisted grinding (UAG) is the state-of-the-art process for machining of brittle-hard materials. In comparison to conventional processes, the main advantages lie in the reduction of tool wear and process forces. Such a vibration system is based on a resonant actuator and a power supply unit generating the alternating current. Both units are interconnected by a contactless energy transfer (CET) system. This system configuration shows one optimal working point at the resonant frequency with maximum amplitude, which is significantly depending on the tool shape. In this work, a piezo-activated tool system is designed to realize non-resonant low-frequency vibrations. Major emphasis is put on the thermal behavior of the piezo drive, particularly on the in-process heating depending on the working frequency. In addition, focus lays on the theoretical and numerical design of the radial operating transducer CET system for a previously set actuator design. As a result, this system configuration offers a fully variable adjustment of the amplitude from under 1 to over $50 \mu \mathrm{m}$ at frequency range. Outside this range, higher amplitudes can be achieved for short periods to the detriment of the fatigue strength according to FKM.
\end{abstract}

Keywords Machining $\cdot$ Vibration $\cdot$ Tool $\cdot$ Piezo

\section{Nomenclature}

$\mathrm{A}_{\mathrm{k}} \quad$ Copper surface $\left[\mathrm{mm}^{2}\right]$

$\mathrm{A}_{\varnothing} \quad$ Copper cross section $\left[\mathrm{mm}^{2}\right]$

a Copper surface height [mm]

b Copper surface width [mm]

$\mathrm{B}_{\max } \quad$ Maximum magnetic flux density [T]

$\mathrm{b}_{\mathrm{Cu}} \quad$ Width of the cooper winding [mm]

$\mathrm{d}_{\mathrm{w} 1} \quad$ Winding diameter [mm]

$\mathrm{f}_{\max } \quad$ Maximum frequency $[\mathrm{Hz}]$

$\mathrm{h}$ Total height [mm]

$\mathrm{h}_{\mathrm{Fe}} \quad$ Core web height [mm]

I Current [A]

$\mathrm{J}_{\max } \quad$ Maximum current density [T]

$\mathrm{k}_{\mathrm{Cu}} \quad$ Filling factor of the cooper winding [-]

$\mathrm{k} \quad$ Coupling coefficient [-]
L Inductance $[\mathrm{H}]$

M Mutual inductance [-]

$\mathrm{N} \quad$ Winding number [-]

$\mathrm{r}$ Radius [mm]

$\mathrm{r}_{\mathrm{a}}$ Outer radius [mm]

$\mathrm{r}_{\mathrm{i}} \quad$ Inner radius [mm]

$\mathrm{r}_{\mathrm{Fe}} \quad$ Iron radius [mm]

$\mathrm{R} \quad$ Resistance $[\Omega]$

$\mathrm{R}_{\mathrm{m}} \quad$ Magnetic resistance [A/Vs]

$\mathrm{t}_{\mathrm{Fe}} \quad$ Iron thickness [mm]

$\delta \quad$ Dielectric power loss of the PZT [-]

$\varphi \quad$ Magnetic flux [Wb]

$\rho \quad$ Density $\left[\mathrm{kg} / \mathrm{m}^{3}\right]$

$\mu_{0} \quad$ Magnetic field constant [Vs/Am]

$\mu_{\mathrm{Fe}} \quad$ Relative permeability of ferrite [Vs/Am]
Jens Brier

brier@ift.at

1 TU Wien, Institute of Production Engineering and Photonic Technologies, Vienna, Austria

\section{Introduction}

Today, a wide range of manufacturing applications use vibration-assisted machining and employ the advantageous process behavior. According to the definition of multiple 
researchers like Lauwers, the combination of manufacturing technology with vibration support belongs to the hybrid manufacturing processes $[1,2]$. The developments on tool side vibration began in the middle of the last century [3]. Today, vibration-assisted machining is incorporated in many fields of application [4]. For new materials such as CFRP and additively manufactured materials, the vibration-assisted machining (VAM) process is a capable technology [5, 6]. A field of application in classic hard materials, for example, is the optical industry with the processing of glasses and lenses made of quartz glass or borosilicate crown glass (BK7) [7-9]. During the grinding of brittle and hard materials according to Inasaki, two crack systems, i.e., median/radial cracks and lateral cracks, occur. The lateral crack system is mainly responsible for material removal; the median/radial crack system is responsible for a reduction of the strength in the area of the crack system [10-12]. In comparison to actual applications of vibration assistance in machining, which are mainly focused on the use of high frequencies, the developed system reveals new options in terms of the flexibility in adapting amplitude and working frequency [13]. A matching energy transmission concept was realized for the previously fixed actuator design. Due to the rotation of the tool, this energy supply solution is realized in the form of a contactless energy transfer (CET) interface designed for machining applications [14]. The working frequency can be practically adjusted in an appropriate range of $100 \mathrm{~Hz}$ to $1 \mathrm{kHz}$. Moreover, the overall concept follows a low-cost approach. Thus, a standard audio amplifier is used as a controller together with the amplifier input from a standard frequency generator for freely adjustable drive frequency.

\section{Design concept}

For the integration of the newly developed actuator system, a DMG MORI Ultrasonic 30 linear machining center with an HSK-E40 adaptor interface is used. This machine is equipped with a force-controlled oscillation system in the tool holder, which is able to realize high frequencies in the ultrasonic frequency range. The machining center platform is used as test setup in order to establish a possibility of direct process comparison between the high frequency and the respective new system. In general, there are two different types of vibration support in machining operations. The first type is a forcecontrolled use and the second operates stroke-controlled. In order to overcome the limitations in the maximum achievable amplitudes at a small range of frequencies by the forcedcontrolled principle, a stroke-controlled system was developed. The amplitude performance depends primarily on the bending membrane design, which is not part of this paper.

\subsection{Vibration system structure}

Figure 1 depicts the installation situation of the vibration system based on a large-stroke piezoelectric multilayer actuator, which mechanically transmits the generated amplitude in the frequency range of $0-1 \mathrm{kHz}$ via a bending membrane to the tool. The main difference between this system and the forcedcontrolled type is the amplitude behavior as a function of frequency.

Figure 2 highlights the main subsystems, which include the CET system (Eq. 1), the power electronics (Eq. 2), and the internal cooling system for the thermal management (Eq. 3). The cooling system can be operated actively and passively and consists of a cooling channel concept with an exchangeable tube that tightly capsules the piezo stack.

By using different materials with different thermal conductivity, a completely passive operation can be achieved through heat conduction. In the case of active cooling, the cutting fluid can be introduced via the existing internal coolant supply in the HSK-E40 tool holder. The cutting fluid is added via the central cooling channel out of the main spindle and runs through channels at the outer cylinder barrel of the tube to the outlet at the bending membrane. The volume flow is subsequently distributed to the cutting zone/tool via the ER16 tool interface.

\section{Design of the CET system}

Due to the requirement of high speeds for grinding and drilling operations, only a contactless energy transfer is possible for the energy to transfer to the actuator. A current-carrying conductor causes a magnetic field, which is quantified by physical properties such as magnetic field strength and flux

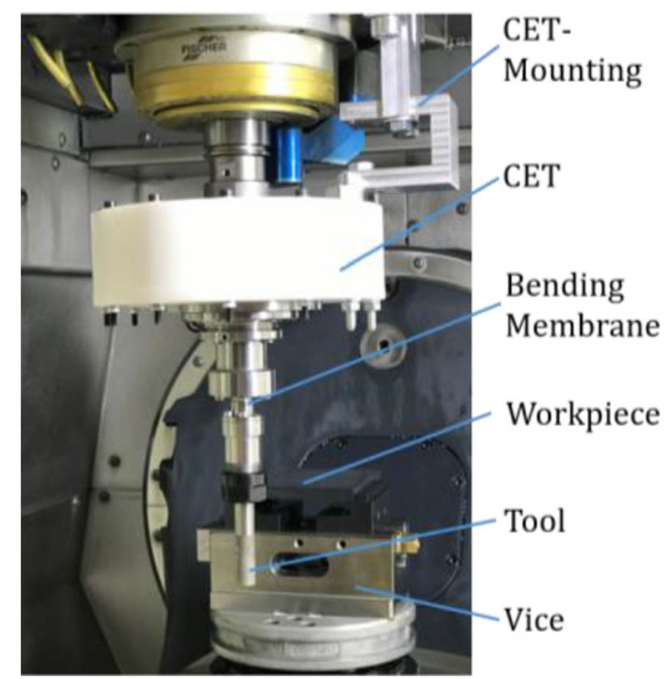

Fig. 1 Implementation of the vibration system in the machining center DMG MORI Ultrasonic linear 30 


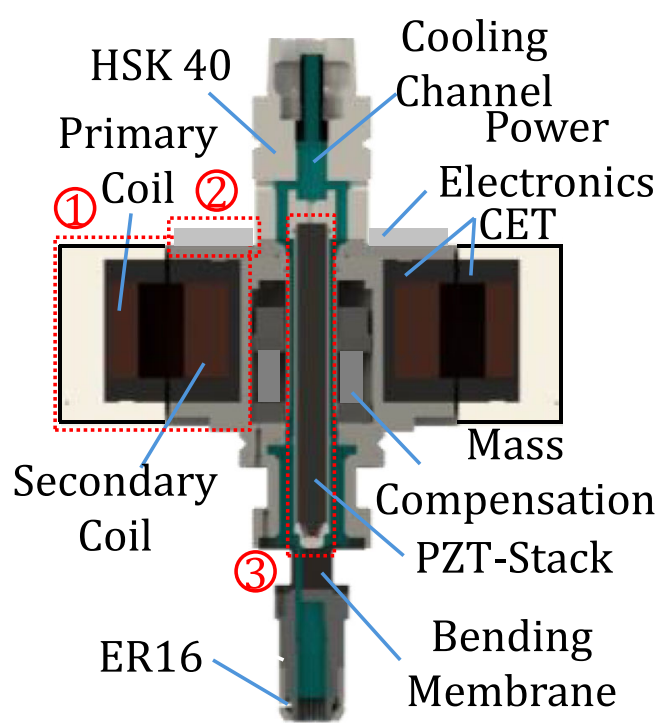

Fig. 2 Structure of the cut 3D model of the IFT vibration system

density. With regard to the operating principle, a general distinction is made between resonant and non-resonant operating modes. In the past, this topic has been the aim of many research projects. A distinction for CET systems can be made by two types according to [15]:

- Axial rotation transmission

- Radial cup core transmitter

A further subdivision of the core is useful, which can consist of solid material. Another option uses a lamination by core sheet metal. Filling the structure with epoxy casting compound, this design comes along with reduced eddy current losses. These losses occur in large-volume iron cores and considerably reduce the output. Depending on the frequency of application, different core structures, such as laminate or solid-core designs, are advisable as the design affects the magnetic properties. Silge and others show the general approach of designing a contactless energy transmission interface [16, 17]. This concept is used in the following analytical design study of the CET system. In the wireless power transmission, a magnetic flux is generated by applying current to the primary coil. The air gap ensures the spatial separation of the coils. However, the magnetic flux in the secondary coil is lower than the induced magnetic flux in the primary coil [17]. Due to leakage flux, only part of the magnetic field of the first coil penetrates the second coil in Eq. 1.

$\phi_{1}=\phi_{12}+\phi_{\sigma 1}$

The windings in the secondary coil generate a voltage by the magnetic field emanating from the primary coil, resulting in a counter-inductance in Eq. 2. This is defined as the mutual magnetic influence of two adjacent electric circuits due to the electromagnetic induction by magnetic flux [17].
$M=\frac{N_{2}+\phi_{21}}{i_{1}}$

The coupling degree of the coils in Eq. 3 depends on the mutual inductance and the two self-inductances of the primary and secondary coils.

$k=\frac{M}{\sqrt{L_{1} L_{2}}}$

\subsection{Equivalent magnetic circuit}

To determine the required dimensions of the coil pairs, a design process in Fig. 3 according to Silge is necessary (cf. [16]). The solution is generated as an output parameter by given input parameters such as the material, the electrical requirements, the operating frequency, the core properties, and the electrical limits of the materials concerning the maximum current and flux density with respect to defined boundary conditions.

\subsection{Geometric design of induction coils}

A substitution of the geometry parameters in Fig. 4 reduces the number of parameters to be optimized in Eqs. 4 to 7. For simplification, the copper area is determined instead of individual copper windings $[16,17]$. The cores of the two coils are a combination of the electrical sheets with a thickness of $0.50 \mathrm{~mm}$ and epoxy resin compound.

$\boldsymbol{h}_{F e}=\frac{\left(\boldsymbol{h}-\boldsymbol{h}_{C u}\right)}{\mathbf{2}}$

$r_{a, 2}=r_{F e, 2}+b_{C u, 2}$

$r_{i, 2}=r_{F e, 2}+b_{C u, 2}+\delta$

$\boldsymbol{r}_{a, 2}=\boldsymbol{r}_{\mathrm{Fe}, 2}+\boldsymbol{b}_{\mathrm{Cu}, 2}+\boldsymbol{b}_{\mathrm{Cu}, 1}+\delta$

\begin{tabular}{|c|c|c|c|}
\hline \multicolumn{2}{|c|}{ Input parameter } & Calculation & Output parameter \\
\hline & Geometry & $\begin{array}{l}\text { Boundary } \\
\text { Conditions }\end{array}$ & \\
\hline \multirow{2}{*}{$\begin{array}{c}\text { Lamination } \\
\mathrm{t}_{\mathrm{Fe}}\end{array}$} & & Geometrical & \\
\hline & Electr. & Dependencies & Coil's \\
\hline \multirow{2}{*}{$\begin{array}{c}\text { Material } \\
\rho_{\mathrm{Cu}}, \rho_{\mathrm{Fe}}, \mu_{\mathrm{r}}\end{array}$} & $\mathrm{U}_{1}, \mathrm{U}_{2}, \mathrm{I}_{2}$ & $\begin{array}{l}\text { Section } \\
\text { - Model of }\end{array}$ & $\mathrm{U}_{1}, \mathrm{U}_{2}, \mathrm{I}_{2}$ \\
\hline & \multirow{2}{*}{$\begin{array}{l}\text { Frequency } \\
\mathrm{f}_{\max }\end{array}$} & Magnetic Circuit & Win \\
\hline \multirow{3}{*}{$\begin{array}{c}\text { Filling } \\
\text { Factor } \\
\mathrm{k}_{\mathrm{Cu}}\end{array}$} & & $\begin{array}{l}\text { - Faraday's Law of } \\
\text { Induction }\end{array}$ & $\mathrm{N}_{1}, \mathrm{~N}_{2}, \mathrm{~d}_{\mathrm{W}, 1}, \ldots$ \\
\hline & \multirow{2}{*}{$\begin{array}{l}\text { Limits } \\
\mathrm{B}_{\max } \mathrm{J}_{\max }\end{array}$} & -Power Balance & Electr. \\
\hline & & Section & $\mathrm{I}_{1}, \mathrm{R}_{1}, \mathrm{~L}_{1}, \ldots$ \\
\hline
\end{tabular}

Fig. 3 Coil and core design process 


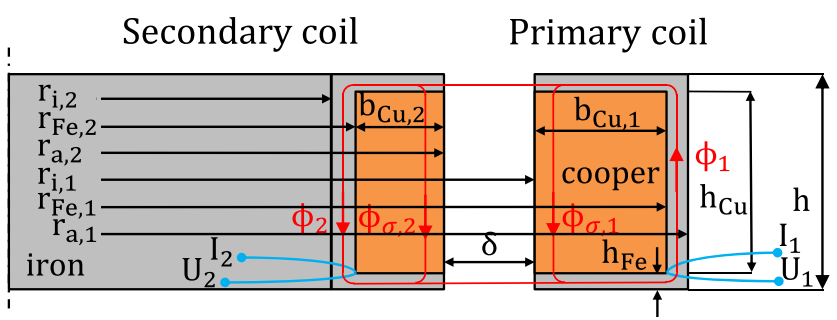

Fig. 4 Geometrical parameter of the coils according to [16]

By using the same cross-sectional areas of the two ferrite cores in Fig. 5, equal flux densities are achieved in each part of the ferrite core if no leakage fluxes occur. Under this assumption, both sides of Eq. 8 and Eq. 9 must be identical $[16,17]$.

$\pi\left(r_{F e, 2}^{2}-r_{i, 2}^{2}\right)=2 \pi r_{F e, 2} h_{F e}$

$\pi\left(r_{\mathrm{Fe}, 2}^{2}-r_{i, 2}^{2}\right)=\pi\left(r_{a, 1}^{2}-r_{F e, 1}^{2}\right)$

\subsection{Mode of magnetic circuit}

Following the procedure for determining the design concept of both coils, the modeling of the magnetic circuit of both inductively connected circuits including the air gap follows Fig. 6 [16].

The linear magnetic resistances of the ferrite cores, the air gap, and the stray field are calculated applying Eq. 10 to Eq. 13. The linear resistance is the independent ratio of voltage and current.

$$
\begin{aligned}
\boldsymbol{R}_{m, F e, 1} & =\frac{2 b_{C u, 1}+h_{C u}}{\pi \mu_{0} \mu_{r}\left(r_{F e, 2}^{2}-r_{i, 2}^{2}\right)} \\
\boldsymbol{R}_{m, F e, 2} & =\frac{2 b_{C u, 2}+h_{C u}}{\pi \mu_{0} \mu_{r}\left(r_{F e, 2}^{2}-r_{i, 2}^{2}\right)} \\
\boldsymbol{R}_{m, \delta, g} & =\frac{2 \delta}{2 \pi \mu_{0} \boldsymbol{r}_{a, 2} \boldsymbol{h}_{F e}} \\
\boldsymbol{R}_{m, \delta, s} & =\frac{1}{\mathbf{0 , 2 6 \pi 2} \mu_{0} \boldsymbol{r}_{a, 2}}
\end{aligned}
$$

\section{a) Primary core}

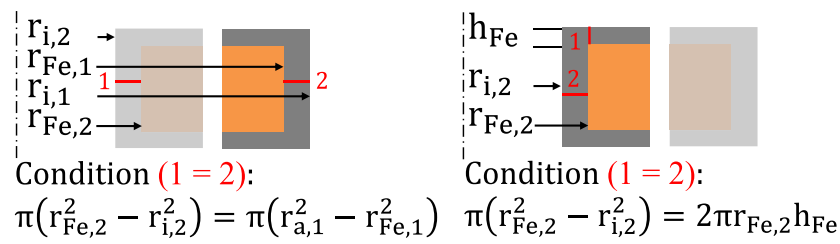

Fig. 5 Overview of the geometrically identical cross-sectional areas for flux density optimization in the ferrite core
The magnetic inductance can estimate the effect of the eddy current loss in Eq. 14 to Eq. 16, which results from the reciprocal resistance of the iron core. For simplification reasons, the eddy currents in the circumferential direction are assumed to be dominant, and only this is considered.

$\boldsymbol{L}_{\boldsymbol{m}, \boldsymbol{F e}, \boldsymbol{i}}=\frac{\mathbf{1}}{\boldsymbol{R}_{\boldsymbol{F e}, i}}, i=1,2$ with

$\boldsymbol{R}_{F e, 1}=\frac{\boldsymbol{t}_{F e} \boldsymbol{h}_{\mathrm{Cu}}}{2 \pi \rho_{F e} \boldsymbol{r}_{F e, 1}}$

$\boldsymbol{R}_{F e, 2}=\frac{\boldsymbol{t}_{F e} \boldsymbol{h}_{C u}}{2 \pi \rho_{F e} \boldsymbol{r}_{F e, 2}}$

The required total magnetic resistance of the primary and secondary side in Eq. 17 depends on the magnetic resistance, the operating frequency, and the magnetic inductance of the core material.

$\boldsymbol{R}_{\boldsymbol{m}, a, i}=\sqrt{\boldsymbol{R}_{\boldsymbol{m}, \boldsymbol{F} e, i}^{\mathbf{i}}+\left(\mathbf{4} \boldsymbol{f} \boldsymbol{L}_{\boldsymbol{m}, \boldsymbol{F} e, i}\right)^{\mathbf{2}}} i=1,2$,

The reduction of efficiency due to leakage losses only occurs at the primary coil. Thus, according to Silge in Eq. 18 to Eq. 20, the loss factor results from the quotient of the individual magnetic resistances for the core, the air gap, and the stray field in the primary coil.

$\sigma=\frac{\boldsymbol{R}_{\boldsymbol{m}, \boldsymbol{F} e, 2}+\boldsymbol{R}_{\boldsymbol{m}, \boldsymbol{\delta}}}{\boldsymbol{R}_{\boldsymbol{m}, \boldsymbol{F} e, 2}+\boldsymbol{R}_{\boldsymbol{m}, \delta}+\boldsymbol{R}_{\boldsymbol{m}, \sigma, i}}$

$\boldsymbol{R}_{m, \sigma 1}=\frac{2 \boldsymbol{h}_{C u}}{\pi \mu_{0}\left(r_{F e, 1}^{2}-r_{i, 1}^{2}\right)}$

$\boldsymbol{R}_{m, \sigma 2}=\frac{2 \boldsymbol{h}_{C u}}{\pi \mu_{0}\left(r_{F e, 2}^{2}-r_{i, 2}^{2}\right)}$

To estimate the inductances of the two coils, the total magnetic resistance of the coils represented by Eq. 21 must be known. This resistance is formed by summing the individual linear total magnetic resistances of the primary and secondary coils and the air gap.

$\boldsymbol{R}_{m, t o t}=\boldsymbol{R}_{m, \delta}+\boldsymbol{R}_{m, a, 1}+\boldsymbol{R}_{m, a, 2}$

The magnetic flux calculated by Eq. 22 describes the circulation of the enclosed total electric current, which is composed of the conduction current and the displacement current. For a cylindrical coil, a good approximation is the multiplication of the current and the number of turns of the coil, the sum of which is equal to the amount of the maximum magnetic flux density multiplied by the flow area of the ferrite core. 
Fig. 6 The equivalent magnetic circuit of the CET for the vibration system

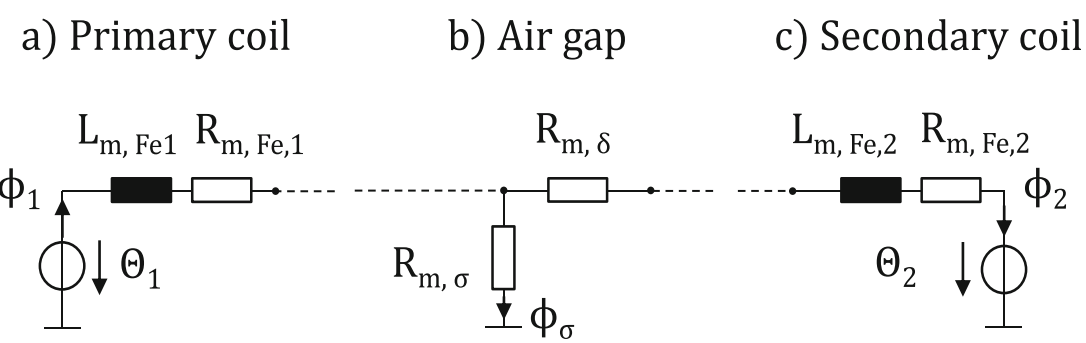

$\Theta_{1}=N_{1} I_{1}=R_{m, t o t \phi \max }=B_{\max } \pi\left(r_{F e, 2}^{2}-r_{i, 2}^{2}\right)$

For the secondary coil in Eq. 23, the same relation between current intensity and the number of turns applies. However, the right side of the equation depends on the multiplicative sum of the area of the winding resulting from the total area multiplied by the winding fill factor and the maximum permissible current density of the winding wire.

$\Theta_{2}=N_{2} I_{2}=J_{\max } k_{C u} h_{C u} b_{C u, 2}$

Faraday's law of induction yields the magnetic secondary coil voltage results in Eq. 24, which is the reason for the magnetic flux in the ferrite core.

$U_{2}=4 f N_{2} B_{\max } \pi\left(r_{F e, 2}^{2}-r_{i, 2}^{2}\right)$

The equation of the ideal transformer in Eq. 25 is followed with Eq. 26 by considering scattering losses and the associated reduction in voltage transmission.

$U_{1} I_{1}=U_{2} I_{2}+\frac{U_{1}^{2}}{\left(4 f L_{1}\right)}$ with

$L_{1}=\frac{N_{1}^{2}}{R_{m, t o t}}$

The final core geometry parameters are shown Table 1 and based on the previous calculation scheme of the CET system.

Table 1 Calculated coil core dimensions of laminated cores of electrical steel M530-A30

\begin{tabular}{lll}
\hline Parameter & Coil 1 & Coil 2 \\
\hline Outside diameter $\mathrm{d}_{1, \mathrm{a}}[\mathrm{mm}]$ & 140.0 & 96.0 \\
Core diameter $\mathrm{d}_{\mathrm{Fe}, 1}[\mathrm{~mm}]$ & 137.0 & 49.5 \\
Inner diameter $\mathrm{d}_{1, \mathrm{i}}[\mathrm{mm}]$ & 99.0 & 48.0 \\
Total amount $\mathrm{h}[\mathrm{mm}]$ & 40.0 & 40.0 \\
Core height $\mathrm{h}_{\mathrm{Fe}}[\mathrm{mm}]$ & 3.5 & 3.5 \\
\hline
\end{tabular}

For the total height, the calculation scheme results in $40.0 \mathrm{~mm}$ of both core sides. Furthermore, the core height is $3.5 \mathrm{~mm}$ for the laminated iron sheets, and the air gap between the first core and second core is $1.50 \mathrm{~mm}$.

\subsection{Coil winding study}

According to Maxwell, the relationship between electric and magnetic fields as well as electrical charges and electric current under the given boundary conditions is described by the following four equations. Coulomb's law in Eq. 27 defines the fact that static charges generate electric fields in space. The second equation (Eq. 28) describes the absence of monopoles and, thus, the conditional closure of field lines. Furthermore, Faraday's law in Eq. 29 describes the electromagnetic induction, which defines the formation of electric vortex fields (closed field lines) and has its origin at a charge. For magnetism, the ampere law in Eq. 30 forms the analogy to the law of induction.

$$
\begin{aligned}
\int E d A & =\frac{Q}{\varepsilon_{0}} \\
\oint B d A & =0 \\
\oint E d s & =-\frac{d}{d t} \int B d A \\
\oint B d s & =\mu_{0} I+\mu_{0} \varepsilon_{0} \frac{d}{d t} \int E d A
\end{aligned}
$$

For the winding study in Fig. 7a, the circuit simulation uses a link with the 2D simulation. This link connects the circuit simulation and the geometry of the coils. ANSYS Maxwell@ considers the windings in the form of the copper area and the number of windings. The area corresponds to the actual copper area without space. The boundary conditions are an input voltage of a sine current source of $1 \mathrm{~V}$ peak-to-peak voltage, a capacitor capacitance of $4500 \mathrm{nF}$, and a resistance of $100 \mathrm{Ohm}$ as the parallel resistor. An increase in the primary windings in Fig. $7 \mathrm{~b}$ causes a higher secondary voltage. This also applies to the induced current depicted in Fig 7c. Modifications in the secondary windings in Fig. 7d cause only a marginal difference in the induced voltage and current of the secondary coil 
Fig. 7 Overview of the simulated results of the winding influence on the CET system at $100 \mathrm{~Hz}$ operating frequency

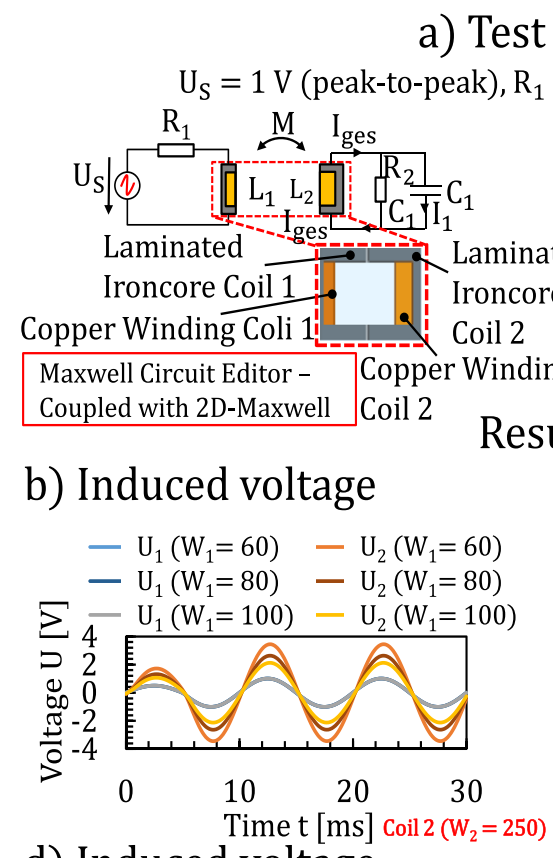

d) Induced voltage

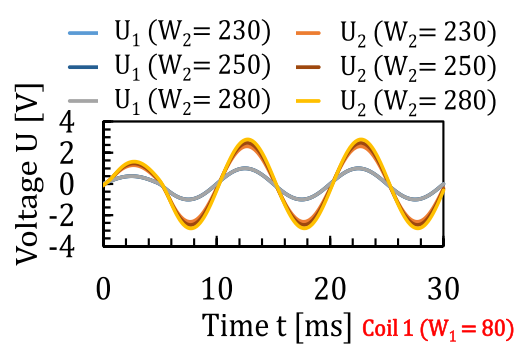

c) Induced current

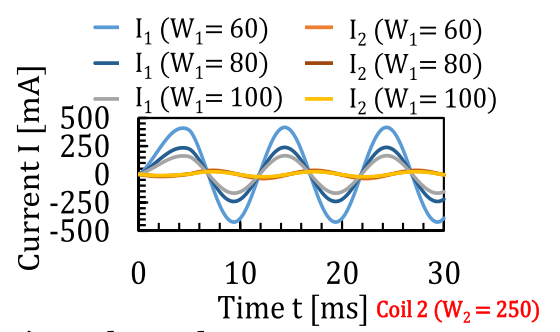

e) Induced current

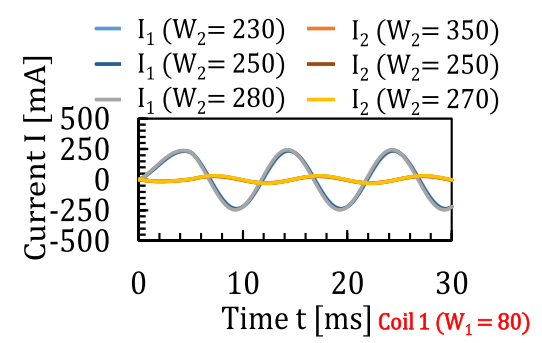

(cf. Fig. 7e). Based on the variation, the number of turns for the primary coil is 80 , and for the secondary coil is 250 .

\section{Power electronics}

The power electronics consist of various electronic components mounted on an aluminum block passively cooled by the ambient air for cooling reasons. A piezoelectric actuator behaves electronically like a capacitor. The stack has a capacity of $4000 \mathrm{nF}$ and should only be driven according to manufacturer information in positive half-wave operation. This requires a full-bridge rectifier setup in the tool system. Table 2 lists the necessary frequency depending on the charge and discharge currents with a peak-to-peak voltage of $150 \mathrm{~V}$. With a triangle or sine function present, the required current is between 0.06 and $0.6 \mathrm{~A}$ for the range $100 \mathrm{~Hz}$ to $1 \mathrm{kHz}$. For an excitation using a square wave function, the current requirement increases to $0.19 \mathrm{~A}$ at $100 \mathrm{~Hz}$ and $1.88 \mathrm{~A}$ at 1 $\mathrm{kHz}$. The required electrical power is determined by Eq. 31 and depends on the actor capacity, the working frequency, and the maximum peak-to-peak voltage.

$$
P_{m}=\frac{1}{2} C U_{p p}^{2} f
$$

The circuit design was optimized and calculated with the simulation program LTSpice from Linear Technologies@ Due to the condition in that only positive half-waves of the voltage are available, the circuit in Fig. 8a needs two additional resistors for piezoelectric charging and discharging. The

Table 2 Required charging and discharging currents for the electrical control of the PZT stacks for $150 \mathrm{Vpp}$ voltage

\begin{tabular}{lll}
\hline For 150V peak-to-peak & Frequency \\
\cline { 2 - 3 } Parameter & $100 \mathrm{~Hz}$ & $1000 \mathrm{~Hz}$ \\
\hline Average peak current $\widetilde{\mathbf{I}}[\mathrm{A}]$ & 0.06 & 0.60 \\
Triangle function $\mathbf{I}_{\text {peak, }} \mathbf{D}[\mathrm{A}]$ & 0.06 & 0.60 \\
Square function $\mathbf{I}_{\text {peak, }} \mathbf{R}[\mathrm{A}]$ & 0.19 & 1.88 \\
Sine function $\mathbf{I}_{\text {peak, }} \mathbf{s}[\mathrm{A}]$ & 0.06 & 0.60 \\
\hline
\end{tabular}


Fig. 8 Overview of the simulated results of the resistance design for the discharge resistance at $1 \mathrm{kHz}$ operating frequency a) Test setup

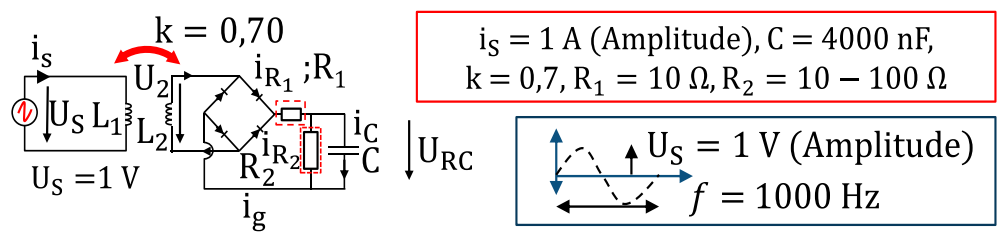

b) Voltage $U_{1,2}$ c) Current resistor $R_{2}$ d) Current capacitor $C$
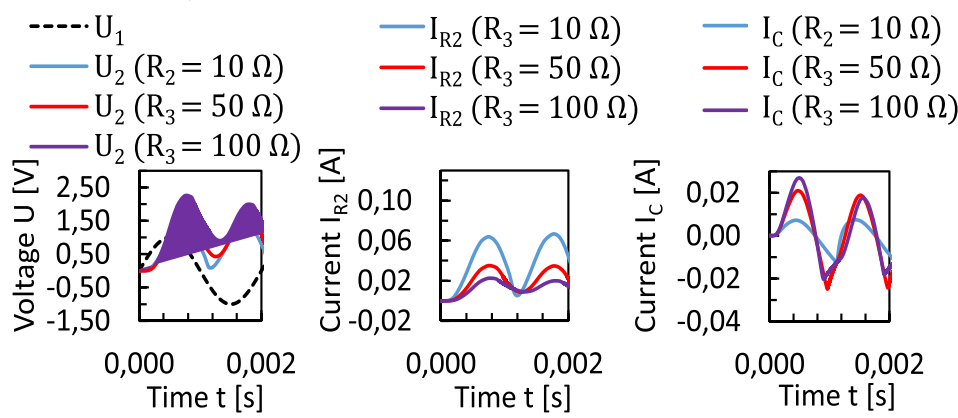

usable current at the capacitor in Fig. $8 \mathrm{~d}$ is $20 \mathrm{~mA}$ (amplitude) with a parallel resistance $\mathrm{R}_{2}$ of $50 \Omega$ for $1 \mathrm{kHz}$ operating frequency.

An increase from 50 to $100 \mathrm{Ohm}$ for resistor $\mathrm{R}_{2}$ in Fig. 8b results in a voltage offset which limits the usable voltage amplitude at the capacitor. A heat sink must avoid overheating.

Figure 9 depicts the electrical behavior during control with the commercial audio amplifier TD7297. The full bridge of the Super Barrier Rectifier (SBR) diodes in Fig. 9a doubles the operating frequency from 100 to $200 \mathrm{~Hz}$. An SBR diode has an extremely low forward voltage and power dissipation compared to standard Schottky diodes. The results in Fig. 9b show the peak-to-peak voltages with the maximum voltage of $20.1 \mathrm{~V}$ at the audio amplifier, and a maximum of $65.7 \mathrm{~V}$ for the secondary side. An increase in the current raises the output power at a maximum output voltage of $20.1 \mathrm{~V}$. A further increase is only possible with a higher amplifier power.
Substantially determined thermal load of the load resistance occurs; this makes optimization of the cooling necessary.

\section{Internal cooling concept}

By thermodynamic definition, energy is transported from a higher temperature medium to a lower temperature medium. The free convection by the macroscopic movement of molecular groups, radiation by energy transport by electromagnetic waves, and heat conduction by molecular activity transfer thermal energy [18]. A transient description of the thermal behavior occurs with the dissipation of a piezo element. However, the dielectric power dissipation $\delta$ required for the calculation of the thermal power loss, according to Melz at 4 to $16 \%$, was set to $20 \%$ for the simulation for higher safety in the design results [19].
Fig. 9 Simulated results of the characterization of the electrical vibration system circuit at $200 \mathrm{~Hz}$ operating frequency

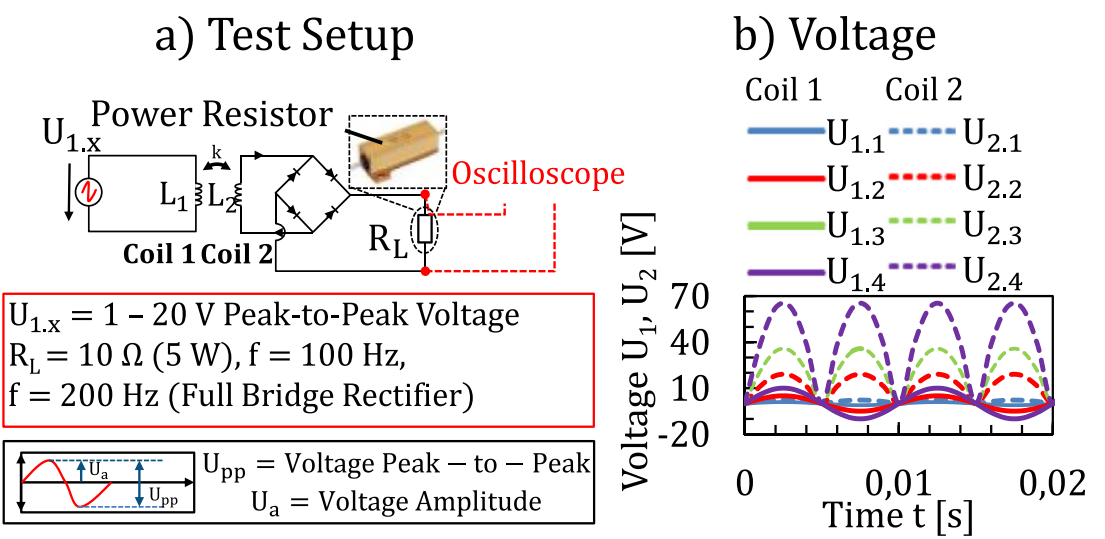




\subsection{Numerical design of PZT stack cooling tube}

The numerical simulation environment ANSYS Workbench (ANSYS WB) was used for the numerical investigation of the cooling functionality. In the concept of the vibration actuator system, the cooling aspect is an important issue that ensures the continuous operation of the piezo actuator element. The thermal limit is the maximum permissible operating temperature of $150^{\circ} \mathrm{C}$. For the design of the piezo cooling tube in Fig. $10 \mathrm{a}$, the material-specific thermal conductivity plays the crucial role. An operational mode without influence of cooling fluid is the worst case under investigation with a constant thermal power loss on the surrounding piezo surface. In the simulation, the heat dissipation properties of stainless steel and brass were investigated. Comparing two different tube materials without external cooling, a temperature of approx. $145^{\circ} \mathrm{C}$ is calculated for the stainless steel tube (cf. Fig. 10c) compared to $83^{\circ} \mathrm{C}$ for brass material (cf. Fig. 10b).

A further increase in the cooling capacity is achieved by passing the internal coolant (cutting fluid) along the tube. For the verification of the FEM models for the two different tube materials, the stainless steel and brass, both results were compared for the frequency range from 0 to $1 \mathrm{kHz}$ with results from real tests from Block [20]. In these tests, the piezo's uncooled operation was compared with water cooling on the one hand and with air cooling on the other hand. The simulation model for brass and stainless steel shows good agreement between the simulated maximum temperatures and the maximum temperature curves by practical experiments in Fig. 11. Using the brass cooling tube, the cooling performance by heat conduction and convection on motionless air is close to the pressure air-cooled system investigated by Block.

\subsection{Numerical design of power resistance cooling}

The thermal power of a resistor is calculated according to Eq. 32 and depends on the current of the capacitor and the size of the parallel resistor.

$P_{R 1}=\frac{U^{2}}{R_{1}}=I_{C}^{2} R_{1}$

For the thermal simulation in ANSYS WB®, the effective value (RMS) for power is used instead of the maximum value. The test setup in Fig. 12 shows the boundary conditions of the simulation. From an electrical optimization with LTSpice®, a value of $10 \Omega$ and $30 \Omega$ follows for the two power resistors. Of
Fig. 10 Overview of simulation results of the thermal power loss of the piezo and the cooling potential of different materials a) System structure b) Maximum temperature of brass tube

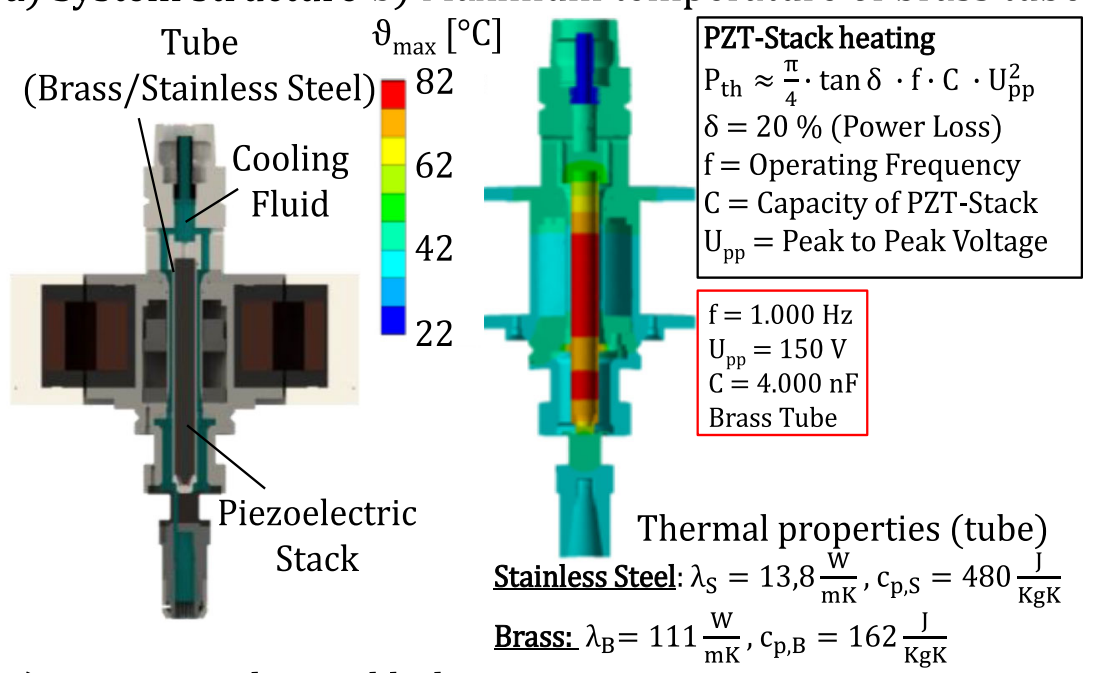

c) Transient thermal behaviour

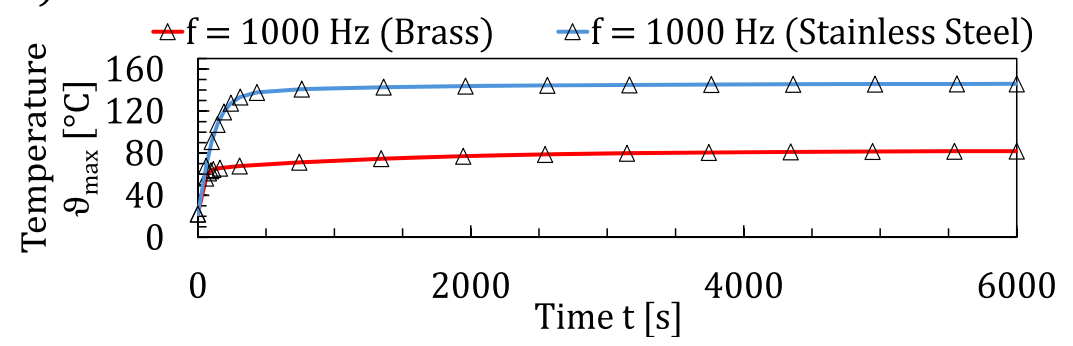




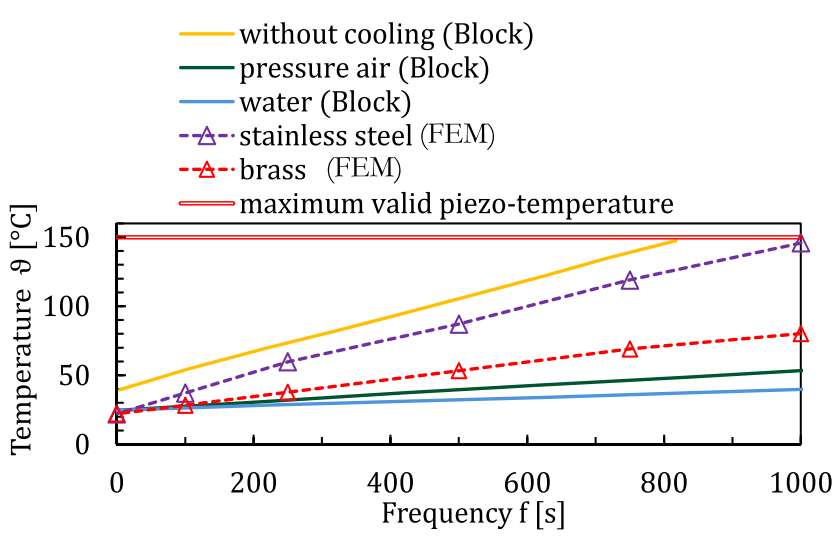

Fig. 11 Simulated results in comparison with results from Block [20]

the two resistors, the stabilizing pre-resistance is determined in terms of thermal load during operation. Hence, the resulting maximum thermal power is over $17 \mathrm{~W}$ for $\mathrm{R}_{1}$. In contrast, the power for the piezo and the parallel resistor is significantly lower and denotes in range of up to $7 \mathrm{~W}$. As mentioned before, the drive frequency of the amplifier at $500 \mathrm{~Hz}$ is leaking because the rectification causes the frequency doubling.

Figure 13 depicts the transient behavior of the power resistors in still air. In this case, the heat transfer coefficient of the aluminum holding block surface is between 0 and $30 \mathrm{~W} / \mathrm{m}^{2} \mathrm{~K}$ (see Fig. 13a). Due to the current load, there is a hightemperature value at the resistors in the circuit (see Fig. $13 \mathrm{c}$ ). With a low heat transfer value of $10 \mathrm{~W} / \mathrm{m}^{2} \mathrm{~K}$, the maximum temperature reaches approx. $185^{\circ} \mathrm{C}$ and decreases to values below $120^{\circ} \mathrm{C}$ as the coefficient increases (Fig. 13d). A heat transfer coefficient of $20 \mathrm{~W} / \mathrm{m}^{2} \mathrm{~K}$ reduces the maximum temperature at levels of under $111^{\circ} \mathrm{C}$. These temperature values are not critical because the maximum acceptable operating temperature value for continuous operation specified by the manufacturer is $250^{\circ} \mathrm{C}$. However, the maximum temperature only occurs at resistor $\mathrm{R}_{1}$, which has the function of a system stabilizing resistor. The other components in the form of the SBR diodes are less temperature sensitive and can withstand maximum heating levels of up to $250^{\circ} \mathrm{C}$. However, this threshold is not reached or exceeded under the used boundary conditions.

\section{Experimental verification}

A low-cost piezo amplifier in the form of a simple digital audio amplifier allows a variable control of the stack with any functions and frequencies. As a current source, a commercial power supply unit with a voltage of $26 \mathrm{~V}$ at a constant current amplifier of $8 \mathrm{~A}$ was used. One limiting factor for the low-cost variant is the low impedance of the primary side, which must be considered in the performance of the output stage selection to avoid overheating. Sufficient cooling of the stack is possible with a simple tube solution, whereby brass material achieves the cooling effect with high thermal conductivity. However, this CET interface is only designed and optimized for low frequencies of up to $1 \mathrm{kHz}$. The vibration system works with a standard low-cost audio amplifier with $160 \mathrm{~W}$ maximum power in combination with a stand-alone standard frequency generator. For the maximum use case of $150 \mathrm{~V}$ voltage and a duration of $6000 \mathrm{~s}$, the measurement of the system results in a maximum amplitude of $85 \mu \mathrm{m}$, and the
Fig. 12 Simulated results of the thermal power loss of the piezo and the resistors at $1 \mathrm{kHz}$ operating frequency

\section{a) Test setup}

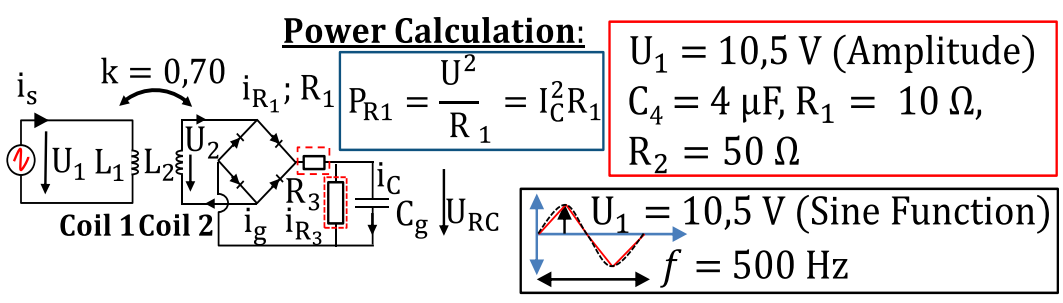

b) Voltage and current

c) Thermal power
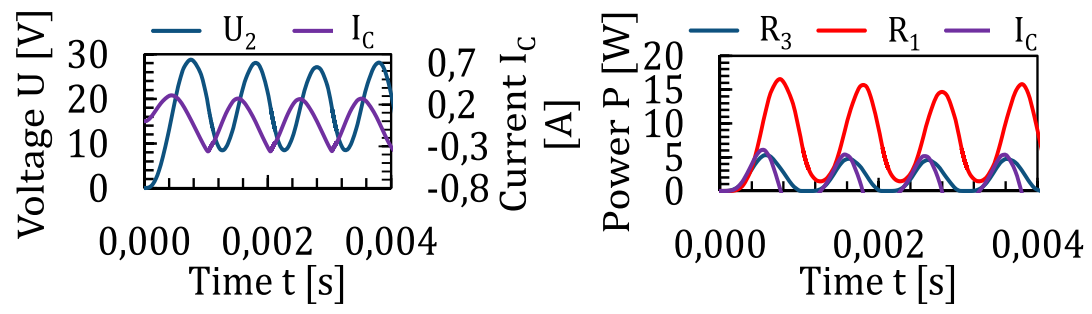
Fig. 13 Simulated results of the thermal power loss of the piezo and the cooling potential of aluminum under different heat transfer coefficients

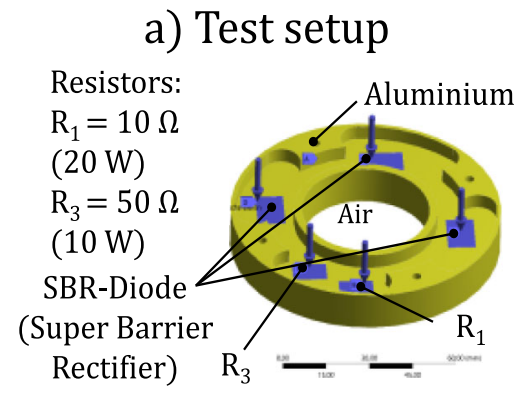

b) Maximum temperature

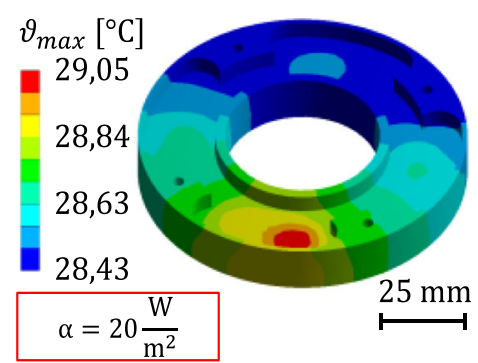

c) Thermal boundaries

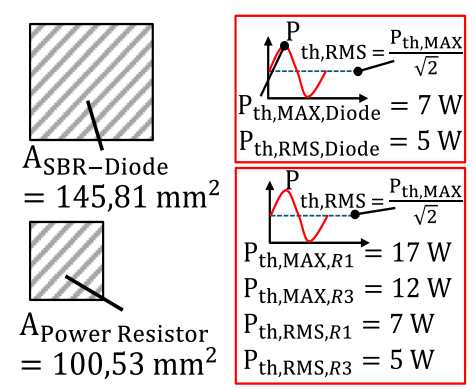

d) Results transient behavior

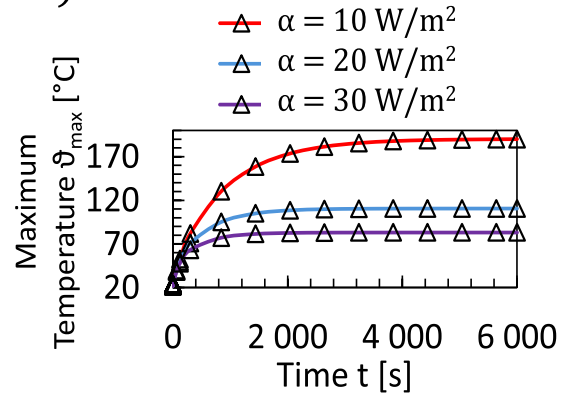

temperature of the brass tube surface measured with a thermocouple rises to $94^{\circ} \mathrm{C}$.

\section{Conclusion}

A contactless power supply solution in the form of a CET interface was developed for an actuated tool system according to the current state of the art for the actuator design realizing low-frequency vibrations at high amplitudes. Simplification in the form of a linearization of the CET system into simple electronic components allows a practical design of the transmission interface. The decisive factor is the transmission ratio of the two coils by the number of windings. The control of the PZT stack by pulsating direct current requires a modification of the circuit in the form of a parallel power resistor to force a discharge. With new SBR diodes, continuous operation is possible due to the combination of low leakage current losses and high thermal load capacity. The drive signal can be used independently of the signal shape for any standard forms such as triangle, square, or even sinusoidal motion. This system configuration offers a fully variable adjustment of the amplitude from under 1 to over $50 \mu \mathrm{m}$ at the respective frequency range. Outside this range, higher amplitudes can be used for short periods to the detriment of the fatigue strength according to FKM guidelines.

Availability of data and materials The data that support the findings of this study are available on request from the corresponding author (JB) upon reasonable request.
Author contribution I confirm that all authors listed on the title page have contributed significantly to the work, have read the manuscript, attest to the validity and legitimacy of the data and its interpretation, and agree to its submission.

Funding Open access funding provided by TU Wien (TUW). The TU Wien as well as the authors want to express great appreciation and gratitude to the Machine Tool Technologies Research Foundation (MTTRF) for supporting the research work in the field of production engineering.

\section{Declarations}

Ethics approval The authors declare that the manuscript does not report on or involve the use of any animal or human data or tissue.

Consent to participate The authors declare that the manuscript does not contain data from any individual person.

Consent for publication The authors declare that the manuscript does not contain data from any individual person. On behalf of all co-authors, I shall bear full responsibility for the submission.

Competing interests The authors declare no competing interests.

\section{References}

1. Lauwers B (2011) Surface integrity in hybrid machining processes. Procedia Engineering 19:241-251

2. Newman ST, Dhokia VG, Nassehi A, Zhu Z (2013) A review of hybrid manufacturing processes - state of the art and future perspectives. Int J Comput Integr Manuf 26(7):596-615

3. Uhlmann B, Daus NA (2011) Ultraschallunterstütztes Schleifen Einsatzvorteile durch ein inovatives Schleifverfahren, BMBF 
4. Fang F, Kang C, O’Toole L (2020) Advances in rotary ultrasonicassisted machining. Nanomanufacturing and Metrology 3:1-25

5. Cong W, Wang H, Ning F, Hu Y, Fernando PKSC, Pei YJ (2016) Surface grinding of carbon fiber-reinforced plastic composites using rotary ultrasonic machining: effects of tool variables. Advances in Mechanical Engineering 8(9):1-14

6. Zhang J, Wang H, Lu WF, Fuh JYH (2018) A study of vibration assisted conformal polishing of additively manufactured structured surface. Proceedings of the Institution of Mechanical Engineers, Part C: Journal of Mechanical Engineering Science

7. Zhao PY, Zhou M, Liu YL, Jiang B (2020) Effect to the surface composition in ultrasonic vibration-assisted grinding of BK7 optical glass. Appl Sci 10(516)

8. Zhu L, Yang Z, Zhang G, Ni C, Lin B (2020) Review of ultrasonic vibration-assisted machining in advanced materials. Int $\mathrm{J}$ Mach Tools Manuf 156(6)

9. Lauwers B, Bleicher F, Ten Haaf P, Vanparys M, Bernreiter J, Jacobs T, Loenders J (2010) Investigation of the process-material interaction in ultrasonic assisted grinding of $\mathrm{ZrO} 2$ based ceramic materials. Proc of 4th CIRP Int. Conf

10. Chen W, Huo D, Shi Y, Hale JM (2018) State-of-the-art review on vibration-assisted milling: principle, system design, and application. Int J Adv Manuf Technol 97:2033-2049

11. Inasaki I, Nakayama K (1986) High-efficiency grinding of advanced ceramics. CIRP Ann 35(1):211-214

12. Bleicher F, Brier J (2016) Schwingungsunterstützte Schleifbearbeitung. Schweizer Schleifsymposium
13. Malkin S, Hwang TW (1996) Grinding mechanism for ceramics. Annals of the CIRP 45(2):569-580

14. Zhu X, Liu L, Qi H (2020) Performances of a contactless energy transfer system for rotary ultrasonic machining applications. IEEE 8

15. Legranger J, Friedrich G, Vivier S, Mipo JC (2007) Comparison of two optimal rotary transformer design for highly constrained applications. IEEE Int Electric Mach \& Drives Conference 2:1546-1551

16. Silge M, Sattel T (2018) Design of contactlessly powered an piezoelectrically actuated tools non-resonant vibration assisted milling. MDPI Piezoelectric Actuators 7(19):1-17

17. Silge M (2016) Design concept for frequency variable electromagnetic contactless energy transfer system powering vibrational actuators in rotary machining. IEEE PEDES

18. Huwig D, Wambsganß P (2020) Modulares Plattformkonzept für die kontaktlose Übertragung von Energie und Daten. RRC power solutions $\mathrm{GmbH}$

19. Melz T (2002) Entwicklung und Qualifikation modularer Satellitensysteme zur adaptiven Vibrationskompensation an mechanischen Kryokühlern, diss. University Darmstadt

20. Block R, Broich B, Pogodzik J, Pertsch P (2016) Piezokeramische Multilayer-Aktoren für den hochfrequenten Betrieb. De Gruyter Oldenbourg, ISBN

Publisher's note Springer Nature remains neutral with regard to jurisdictional claims in published maps and institutional affiliations. 